\title{
Protein Kinase C Beta Type
}

National Cancer Institute

\section{Source}

National Cancer Institute. Protein Kinase C Beta Type. NCI Thesaurus. Code C42733.

Protein kinase $C$ beta type (671 aa, $\sim 77 \mathrm{kDa}$ ) is encoded by the human PRKCB gene. This protein plays a role in protein phosphorylation, lipid-mediated signaling, apoptosis and cell proliferation. 